\section{Biodiversity: involvement of local people is crucial}

SIR - It is true that we can divide the environment up into services that can be priced as discussed in your News Feature "Dollars and sense ${ }^{n}$ (Nature 437, 614-616; 2005), even the most sacred. However, there is little evidence that economically sound management systems in themselves engender sustainable utilization. We are frequently reminded of this by bulletins on the state of the world's native forests or by the collapse in several UK offshore fisheries.

Economically driven management systems often seem to lack the qualities of care and close monitoring that are needed in looking after the rare, vulnerable and endemic. How we manage our environment may be a more fruitful question to ask than why. Revenue from state-run protected areas must be both administered transparently and captured locally: these were rated the most important lessons for sustainability at a 1994 conference on development of protected area strategies for African, Caribbean and Pacific countries.

Similarly, local 'ownership' of natural resources and disincentives to cheat may be prerequisites for their long-term sustainable use, as the exemplary state of the Falkland Island fisheries reminds us.

Good interpretation of scientificvalues and respect for our living heritage also encourage local investment (in the larger sense of the word) in the environment. They are surely as important as economic returns in promoting long-term sustainable use of ecosystem services and the protection of biodiversity. Martyn G. Murray ${ }^{\star}$, Jacqueline A. Yellandt *Institute of Evolutionary Biology, University of Edinburgh, WestMains Road, Edinburgh EH9 3JT, UK

$\dagger 2$ Wheatsheaf Cottages, Sarratt, Rickmansworth WD3 6BR, UK

\section{Space triumph reveals new spirit of openness in China}

SIR - Although I read with interest your news story "China launches plans for space exploration as taikonauts touch down (Nature 437, 1075; 2005), you do not mention a great change that is taking place in China with regards to space missions - a prompt and thorough openness to the public.

Unlike China's last manned space flight in 2003, the recent mission included a live television broadcast from launch to landing that was made widely available to the public. You could watch images from the electronic cameras installed on the interior and exterior of the module in real time.

Journalists, including those from Taiwan, were also given free entry to the Jiuquan satellite launch centre, the Beijing aerospace command and control centre, and the landing site in Inner Mongolia. Some journalists were even invited to take part in astronaut training, and try out space suits and food; recording the details of such secret places and instruments would have been inconceivable not so long ago.

More officials have been interviewed by the mass media and openly discussed details of Chinese space exploration technology and plans than ever before. This openness represents a new confidence and selfassurance among scientists in China. Bin Wang

Department of Pharmacology,

Nanjing Medical University, 140 HanZhong Road, Nanjing 210029, P.R. China

\section{Intelligent, social rat can find joy in a hostile world}

SIR — One has to admire the guile and tenacity of the lone rat described by James Russell and colleagues ("Intercepting the first rat ashore," Nature 437, 1107; 2005). This rat lived for ten weeks on a small, booby-trapped island, visited by trained rat-killing dogs, before swimming a quarter of a mile to a neighbouring island, where he survived a further two months of concerted efforts to eliminate him.

When the story aired on national public radio in the United States, the tone was contrived to foster the 'sinister rat' stereotype. I, for one, sympathize with this castaway doing his best in a hostile world. Russell and his colleagues show us that rats are intelligent, and other studies show them to be social creatures capable of a range of emotions, including joy (see, for example, J. Panksepp and J. Burgdorf Physiol. Behav. 79, 533-547; 2003). They deserve more consideration than we give them.

Jonathan Balcombe

Physicians Committee for Responsible Medicine, 5100 Wisconsin Avenue, NW, Suite 400,

Washington DC 20016, USA

\section{Peer-review system could gain from author feedback}

SIR - The ever-growing number of submissions to many journals has necessarily increased the number of scientists serving as reviewers. Although the majority of these perform their duty honourably and provide valuable feedback to the authors, some produce bad or even damaging reviews, which may not be filtered by the editors.

I believe anonymity is important for the peer-review process, but some power could also be granted to the authors in order to balance the equation. The flexibility of online systems could be employed to establish a feedback mechanism that may help journals weed out rogue reviewers.

One can imagine a scenario in which all authors would be asked to complete an online questionnaire about the reviews of their manuscript. The questionnaires could be anonymous, but should allow the journal to cross-reference the feedback with the name of each reviewer. Once sufficient data have accumulated, the journal will be able to identify reviewers who are serial offenders and decide not to approach them again.

Gathering feedback from the authors and using that to improve the peer-review process is a simple way of humanizing an increasingly electronic process.

\section{Alon Korngreen}

Faculty of Life Sciences and the Leslie and Susan Ganda Brain Research Center, Bar-llan University, Ramat-Gan 52900, Israel

\section{How Wallace and Dampier faced tsunamis at sea}

SIR - A favourite bedtime book of mine is Alfred Russel Wallace's The Malay Archipelago (Macmillan, London, 1869). During my last read I found the following description of what sounds like a tsunami. Wallace in turn quotes from William Dampier's Continuation of a Voyage to New Holland in the Year 1699 (Knapton, London, 1703).

"We heard a dull roaring sound like a heavy surf, .... the roar increased, and we saw a white line of foam coming on, ... as our boat rose easily over the wave. At short intervals ten or a dozen others overtook us with great rapidity, and then the sea became perfectly smooth as before. I concluded at once that these must be earthquake waves; and on reference to the old voyagers we find that these seas have long been subject to similar phenomena.

"Dampier encountered them near Mysol and New Guinea, and described them as: '... strange tides, that ran in streams, making a great sea, and roaring so loud that we could hear them before they came within a mile of us. ... These ripplings commonly lasted ten or twelve minutes, and then the sea became as still and smooth as a millpond. ... We had one night several of these tides, ... we heard them a long time before they came.' ...

"Some time afterwards I learnt that an earthquake had been felt on the coast of Gilolo the very day we had encountered these curious waves."

Jeyaraney Kathirithamby Department of Zoology, University of Oxford, South Parks Road, Oxford OX13PS, UK and St Hugh's College, StMargaret's Road, Oxfard OX2 6LE, UK 